1

2

3

\title{
Event-related potential correlates of sound organization: early sensory and late cognitive effects
}

\author{
O. Szalárdy ${ }^{\mathrm{a}, \mathrm{b}}$, T. Bőhm ${ }^{\mathrm{a}, \mathrm{c}}$, A. Bendixen ${ }^{\mathrm{d}}$, \& I. Winkler ${ }^{\mathrm{a}, \mathrm{e}}$ \\ ${ }^{a}$ Institute of Cognitive Neuroscience and Psychology, Research Centre for Natural Sciences, \\ Hungarian Academy of Sciences, Hungary \\ ${ }^{\mathrm{b}}$ Department of Cognitive Science, Faculty of Natural Sciences, Budapest University of \\ Technology and Economics, Hungary \\ ${ }^{\mathrm{c}}$ Department of Telecommunication and Media Informatics, Budapest University of Technology \\ and Economics, Hungary \\ ${ }^{\mathrm{d}}$ Institute for Psychology, University of Leipzig, Germany \\ ${ }^{\mathrm{e}}$ Institute of Psychology, University of Szeged, Hungary
}

Address correspondence to:

István Winkler

Institute of Cognitive Neuroscience and Psychology, Research Centre for Natural Sciences, Hungarian Academy of Sciences

P.O. Box 398

H-1394 Budapest, Hungary

Phone: +3613542296

Fax: +3613542416

e-mail: winkler.istvan@ttk.mta.hu 
Keywords: perceptual bistability; event-related brain potentials (ERP); oddball paradigm; early vs. late processes 


\section{Introduction}

Ambiguous stimulus configurations allow more than one interpretation of the same physical input and they often result in perceptual bi-/multistability (Blake \& Logothetis, 2002; Leopold \& Logothetis, 1999; Pressnitzer \& Hupé, 2006). For example, Necker's cube can be perceived in two different ways. When the cube is slowly rotated, the direction of the perceived rotation depends on the currently dominant perceptual alternative (Purves \& Andrews, 1997). This as well as similar observations in the auditory modality (Bregman, 1990; Gutschalk et al., 2005; Schadwinkel \& Gutschalk, 2011; Sussman, Ritter, \& Vaughan, 1999; Winkler, Takegata, \& Sussman, 2005) suggest that the current percept modulates the processing of incoming sensory information. Context-dependent processing of information is an important facet of human cognition as it, for example, allows us to identify objects quickly and with minimal processing (Bar, 2007). One important question for research is to determine the stage at which percept-dependent effects take place (Brancucci \& Tommasi, 2011). Results of some studies (Gutschalk, et al., 2005; Müller, Widmann, \& Schröger, 2005) suggested that the information extracted from incoming stimuli (feature analysis) can be affected by the currently held perceptual organization (early effects). In contrast, other results (Winkler, et al., 2005) suggested that only the evaluation of the extracted information is modulated by the perceptual organization (for a recent review of early vs. late effects in the visual domain, see Railo, Koivisto, \& Revonsuo, 2011). The current study employed event-related brain potentials (ERP) to clarify this issue and to test whether the previously observed early percept-dependent ERP differences represent sensory- or task-related processes.

The high temporal resolution of ERPs allows one to establish the timing of effects on perceptual processes, while determining the affected component(s) helps to identify the corresponding functions. Short-latency sensory ERP responses of sound processing (also called exogenous components), such as P1 and N1, are usually associated with the processing of the physical stimulus properties; these components are strongly modulated by attentional processes (Näätänen \& Picton, 1987; Picton, 2010; Snyder, Alain, \& Picton, 2006). Longer-latency ERP responses such as N2 and P3a (endogenous components) are known to reflect higher-order cognitive processes (Picton, 2010) including conscious perception of sensory events (Leppert, Goodin, \& 
Aminoff, 2003). Specifically, the N2 component has been linked with stimulus classification (Ritter \& Ruchkin, 1992; Ritter, Simson, Vaughan, \& Friedman, 1979), whereas subcomponents of the P3a have been associated with attention switching (Escera, Alho, Schröger, \& Winkler, 2000; Friedman, Cycowicz, \& Gaeta, 2001; Polich, 2007; Schröger, 1996) or a contextual evaluation of novelty (Horváth, Winkler, \& Bendixen, 2008).

We investigated the ERP correlates of the consciously experienced auditory percept by utilizing a bistable auditory stimulus configuration, the auditory streaming paradigm (van Noorden, 1975). In this paradigm, a repeating three-tone pattern is presented to listeners: $A B A$, where $A$ and $B$ differ in some feature, such as pitch, and the tone triplets are separated by a silent interval equaling the sum of the common tone duration and the inter-stimulus interval. Depending on the amount of feature separation between $A$ and $B$ and the presentation rate, listeners tend to perceive the sounds as a single coherent sequence (termed the integrated percept) or as two sound streams (termed the segregated percept), one consisting only of the $A$, the other of only the $B$ tones (Bregman, 1990; van Noorden, 1975). For longer (> 1 minute) sequences of this type, perception switches back and forth between the two sound organizations (Anstis \& Saida, 1985; Bendixen, Denham, Gyimesi, \& Winkler, 2010; Denham \& Winkler, 2006; Hill, Bishop, Yadav, \& Miller, 2011; Pressnitzer \& Hupé, 2006; Roberts, Glasberg, \& Moore, 2002).

Using the auditory streaming paradigm, three previous studies investigated percept-dependent changes in sound processing. The results of these studies are not consistent regarding the stage of the processing influenced by perceptual organization. Gutschalk and colleagues' (2005) results showed percept-dependent modulation of the auditory magnetic P1 and N1 responses (Picton, 2010), suggesting that perceptual organization affects early sensory processes. In contrast, in Winkler et al.'s study (2005) short-latency responses were affected only by the parameters of the stimulus configuration, whereas a later, negative component peaking ca. $175 \mathrm{~ms}$ from stimulus onset varied together with the listener's perception. Although both studies used the auditory streaming paradigm with stimulus parameters promoting the perception of the integrated and segregated organizations with approximately equal probabilities, two differences between the procedures and the strategy of data analysis may have resulted in the contrasting findings. First, in Gutschalk et al.'s study (2005; Experiment 2), listeners were instructed to focus their attention differently when experiencing the two possible percepts: whereas listeners were only instructed 
to report the perception of the integrated percept, they were to focus either on the high or on the low stream, when experiencing the segregated percept. In contrast, Winkler et al.'s (2005) participants were only required to continuously indicate the experienced sound organization. This procedural difference may have resulted in differences in the allocation of attention in the two studies, and attention is known to modulate the P1 and N1 ERP components (Näätänen \& Picton, 1987; Picton, 2010; Snyder, et al., 2006). Therefore, it is not clear whether the early effects observed by Gutschalk et al. (2005) represent direct modulations of sensory processes or whether they were mediated by task-related top-down processes. Second, Winkler et al.'s (2005) data analysis focused on responses to occasional omissions of the middle $(B)$ tone of the $A B A$ triplets. Thus, unlike Gutschalk et al.'s (2005) results, which describe the processing of the regular sounds, Winkler et al.'s (2005) results characterize deviance detection as a function of the perceived sound organization with no exogenous responses triggered by the deviant events (i.e., the deviant events were caused by the omission of an expected sound). Müller et al. (2005) also showed that the N1 amplitude was influenced by whether participants heard the sound sequences as segregated or integrated. However, these authors manipulated sound organization by presenting the tones at different delivery rates and did not check how participants actually perceived the sound sequence, as they were instructed to ignore the sounds. Therefore, the results of this study cannot be directly compared with those of Gutschalk et al.'s (2005) and Winkler et al.'s (2005) and due to the lack of attention control, possible attentional effects cannot be ruled out.

In the current study, we measured the ERP correlates of perceived sound organization in sequences composed according to the auditory streaming paradigm while listeners were instructed to continuously indicate the perceived sound organization. The $A$ and $B$ tones differed in frequency (pitch), and their regular presentation was infrequently violated by exchanging the second $A$ tone of the triplet for a tone which was either slightly (termed small deviants) or moderately (termed moderate deviants) lower in frequency than the standard $A$ tones. Participants were instructed to continuously mark their perception during the tone sequences, with no additional instructions in terms of the allocation of attention.

We expected early effects of perceptual organization on auditory processing to be reflected by percept-dependent modulations of the exogenous ERP components (such as P1 or N1), whereas 
late effects should appear as modulations of endogenous components such as the N2 and/or P3a. With respect to the controversy between the two above reviewed studies (Gutschalk, et al., 2005; Winkler, et al., 2005), if the differences in finding early vs. late percept-dependent ERP effects stemmed from measuring responses for regular vs. irregular sounds, we should then expect to find in the current experiment that perceptual organization influences the P1 and N1 components elicited by the regular tones and the N2 elicited by the deviant tones. If, however the contrasting results were due to differences in the allocation of attention in the two studies, then similarly to Winkler et al. (2005) we should find only late percept-dependent effects, as the instructions in the current study were similar to the ones used in that study.

Finally, based on Helson's adaptation level theory (Helson, 1964) one could expect an interaction between the effects of perceptual organization and the amount of deviation. This is because while perceiving the integrated organization, the range of frequencies is wider within the group of tones belonging to the same perceptual unit than when one perceives separate homogeneous streams. Therefore, in the segregated case, smaller amounts of deviation could become more salient. In contrast, larger deviations could induce equal salience under the two perceptual organizations. Thus on this hypothesis, we should observe an interaction between the perceptual organization and the amount of deviation.

\section{Methods \\ Participants}

Twenty-four young healthy volunteers took part in the experiment (19-26 years of age, average: 21.5, 13 female). All of them had normal hearing as their hearing threshold did not exceed $25 \mathrm{~dB}$ $\mathrm{HL}$ or $10 \mathrm{~dB}$ difference between the ears in the 250 to $8000 \mathrm{~Hz}$ frequency range. None of the participants took any medications affecting the central nervous system. Written informed consent was obtained from the participants after the experimental procedures were explained to them. The study was approved by the Ethical Committee of the Institute for Psychology of the Hungarian Academy of Sciences. Participants received modest financial compensation. 


\section{Stimuli and conditions}

Participants were presented with continuous sequences of $A B A_{-}$cycles where $A$ and $B$ stand for pure tones differing only in frequency and '_, stands for a silent gap equaling the common tone duration of $75 \mathrm{~ms}$ (including $10 \mathrm{~ms}$ linear onset and $10 \mathrm{~ms}$ linear offset ramps). Individual tones were delivered with a uniform $150 \mathrm{~ms}$ onset-to-onset interval. Sound intensity was set $40 \mathrm{~dB}$ above the participant's individual hearing threshold established for the same $A B A_{-}$sequence as was used in the experiment. The frequency of the $A$ tones was $400 \mathrm{~Hz}$ and $B$ tones $(504 \mathrm{~Hz})$ were four semitones (ST) higher than the $A$ tones. Deviant tones always appeared in the position of the second $A$ tone in the $A B A_{-}$cycle (Figure 1). Small deviants were $0.5 \mathrm{ST}$, moderate deviants were 1.5 ST lower than the regular (standard) $A$ tones. These parameters were selected on the basis of a behavioral pilot experiment. The goal of this pilot was to find parameters with which the integrated and segregated percepts are reported in approximately equal percentage of the time. The amount of deviation was set so that even the moderate deviants did not cause a perceptual reset (Cusack, Deeks, Aikman, \& Carlyon, 2004). This was tested by comparing the percept proportions between sequences with only standard $A B A_{-}$triplets with those obtained for sequences including deviant tones. Neither in the pilot nor in the main experiment did we find a significant difference in the percept proportions between sequences with and without deviants (see below; results of the pilot experiment are not reported as they were qualitatively identical with those of the main experiment). Thus the introduction of the deviants did not significantly change the dominance percentage of the integrated and segregated percepts compared with the same tone sequence having only standard tones. Each deviant appeared with 5\% probability. Deviants were pseudo-randomly intermixed in the sequence with the criterion that successive deviants were separated by at least two standard $A B A_{-}$cycles and that no deviant tones were introduced within the first $30 \mathrm{~s}$ of the sequences. Overall, 15 stimulus blocks were delivered, each lasting for 5.5 minutes and consisting of 550 ABA_ cycles. One stimulus block, delivered at a random position within the experimental session, did not contain deviants and was used for control purposes. The remaining stimulus blocks included 55 deviant tones, each (small and moderate deviants, together). 


\section{Experimental design}

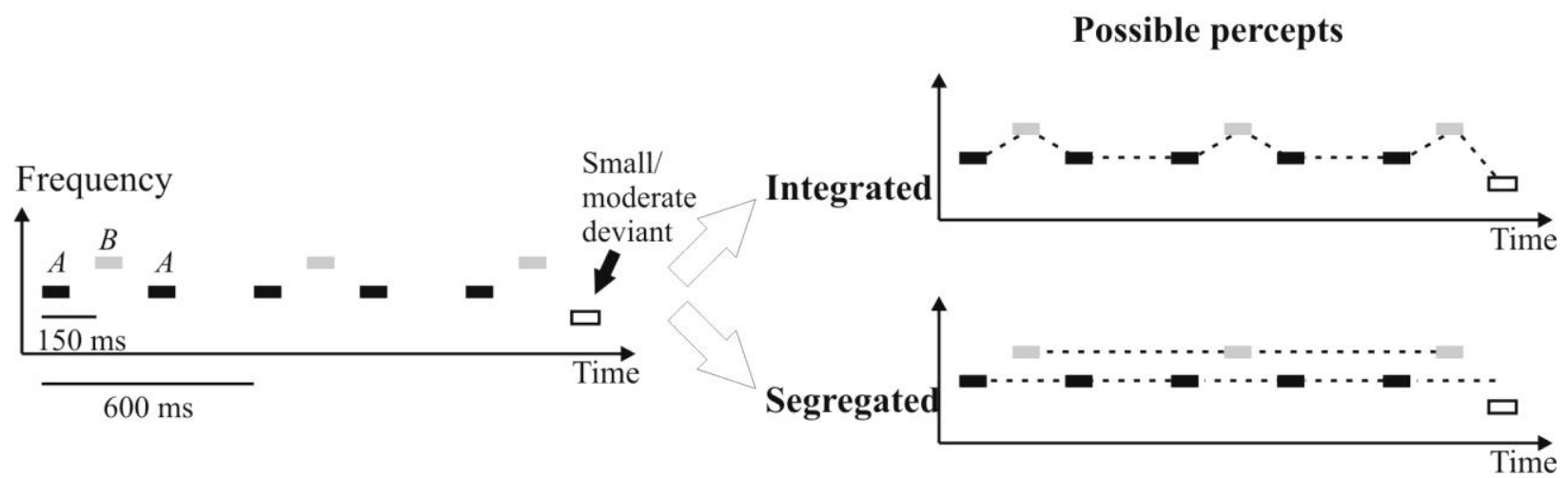

Figure 1. Experimental design. The left panel shows the structure of the sequences including the deviant tones. The black and grey rectangles represent the different tones (A and B). The right panel shows the possible perceptual organizations.

\section{Procedure}

Participants were seated in a comfortable chair in a sound-attenuated experimental chamber located at the Institute of Cognitive Neuroscience and Psychology, Research Centre for Natural Sciences, Hungarian Academy of Sciences. Sound sequences were presented binaurally with Sennheiser HD 600 headphones. Participants were instructed to listen to the sequence and continuously mark their perception using two response keys, holding one in each hand. They were asked to release both response keys when they did not hear any regularly repeating sound pattern (termed the neither percept). One of the keys was designated to indicate hearing either a repeating $A$ and/or a repeating $B$ tone, with the $A$ tones being connected only with $A$ and $B$ tones only with $B$ tones (e.g. $A \_A \_A \ldots$ and/or $B \_\_B \_B \ldots$; termed the segregated percept). The other response key was to be depressed when a regularly repeating pattern including both $A$ and $B$ tones was heard (e.g., $A B A \_A B A_{-} \ldots$; termed the integrated percept). Finally, both keys were to be depressed concurrently when the participant heard a repeating pattern in which the $A$ and the $B$ tones were linked together (e.g., $A B \_A B \ldots$ ) and, at the same time, another repeating pattern made up of identical tones (e.g., $A_{\ldots} A_{\text {_ _ _ }}$ _...; t termed the both percept). The state of the response keys was sampled at $250 \mathrm{~Hz}$. In instructing the participants, the experimenter emphasized to always report the currently perceived sound organization and switch between the response keys as soon as their perception changed. The arrangement of the two response keys 
was balanced across participants to eliminate the effects of handedness. Participants were instructed to fixate on a cross shown in the middle of a computer screen located ca. $1 \mathrm{~m}$ in front of their head, and to keep their eyes open during the stimulus blocks. The experimenter explained the instructions to the participant with the help of auditory and visual illustrations and then made sure that the instructions were understood by presenting short tone sequences which strongly promoted either integration or segregation and asking the participant to press the corresponding response key(s). Depending on the participant, the instruction period lasted for 1520 minutes. In the main experiment, participants were allowed to relax for about two minutes between stimulus blocks with longer breaks inserted whenever needed. On average, the experimental session lasted for 240 minutes, including pauses, training, as well as electrode application and removal.

\section{EEG recording}

The electroencephalogram (EEG) was recorded with $\mathrm{Ag} / \mathrm{AgCl}$ electrodes and Synamps amplifiers (Neuroscan Inc.) at the Fp1, Fp2, F7, F3, Fz, F4, F8, FC5, FC1, FC2, FC6, T7, C3, Cz, C4, T8, CP5, CP1, CP2, CP6, P7, P3, Pz, P4, P8, O1, Oz, O2 scalp locations (10-20 system) as well as at the left and right mastoids (LM and RM). The common reference electrode was attached to the tip of the nose and the ground electrode to the forehead. The electrooculogram (EOG) was recorded between two electrodes attached above and below the left eye (vertical EOG) and between two electrodes placed lateral to the left and right outer canthi (horizontal EOG). The sampling rate was $1000 \mathrm{~Hz}$ and signals were on-line filtered with a $40 \mathrm{~Hz}$ low-pass filter.

\section{Data analysis}

From the continuous record, perceptual phases were extracted. A perceptual phase is a continuous time interval during which the same combination of response keys was depressed indicating that the same sound organization was perceived during the interval (which was preceded and followed by a different percept). Thus the sequence of the sampled response key combinations was analyzed in terms of a sequence of perceptual phases, each having two 
parameters: type of percept (segregated, integrated, both, or neither) and duration of percept. Only the integrated and segregated perceptual phases were analyzed statistically, because the overall probability of the other two percepts ("both" and "neither") was marginal $(<6.7 \%$ together on average).

\section{$\underline{\text { Behavioral data }}$}

Because participants may have been inaccurate in synchronizing their button press and release movements with their percept (e.g., when switching from marking segregated to marking integrated), perceptual phases shorter than $300 \mathrm{~ms}$ were removed from the analysis (cf. MorenoBote, Shpiro, Rinzel, \& Rubin, 2010). The proportion of the percepts was calculated as the percentage of time spent in one or another percept. The percept proportions measured in the control stimulus block were compared by dependent Student's $t$ test with those averaged from the 14 stimulus blocks with deviants to check the effects of the presence of deviants on the perception of the stimulus sequences.

\section{$\underline{\text { ERP data }}$}

EEG was down-sampled to $250 \mathrm{~Hz}$ and off-line filtered with a Kaiser passband filter between 0.1 and $20 \mathrm{~Hz}$. Epochs of different time windows were formed (see below) and averaged for standard and deviant ERPs after rejecting those epochs in which the signal range throughout the epoch was below $0.1 \mu \mathrm{V}$ or above $100 \mu \mathrm{V}$ at any channel. Five participants out of the twentyfour had fewer than 75 artifact-free deviant-stimulus ERP responses either in the integrated or the segregated percept. Data from these participants were excluded from the analysis. Epochs from the first $30 \mathrm{~s}$ of each stimulus block were also excluded from the analysis to reduce the effect of the first percept on the results. The first percept has been reported to have substantially different characteristics compared with those of the remaining percepts in the stimulus blocks (Denham, Gyimesi, Stefanics, \& Winkler, 2010, in press). Integrated-minus-segregated ERP difference waveforms were calculated.

\section{$\underline{\text { Responses to the standard tones }}$}


From the continuous EEG record, epochs of $825 \mathrm{~ms}$ duration were extracted for the standard tone triplets, starting $75 \mathrm{~ms}$ before the onset of the first $A$ tone $(A 1)$. The baseline was set to the 75 -ms interval preceding $A 1$. Local maxima were identified on the central $(\mathrm{Cz})$ group-average ERP waveforms. Both $A 1, B$, and the following $A(A 2)$ elicited a positive-going peak at about $75 \mathrm{~ms}$ from tone onset followed by two successive negative-going peaks at about 110 and $200 \mathrm{~ms}$. These waveforms were identified as the P1, N1, and N2 components, respectively (Figure 2, left panel). Note that with a fixed short SOA, the late ERP components elicited by the previous tone and the early components elicited by the next one cannot be fully separated. This issue may have affected the measurement of the early components elicited by $B$ and $A 2$, and the late components elicited by $A 1$ and $B$. Amplitudes were measured at F3, Fz, F4, C3, Cz, C4, P3, Pz and P4. Time windows for analyzing the ERP responses to $A 1$ tones were set at 69-99, 101-131, and 181-211 ms from $A 1$ onset. Time windows for analyzing the ERP responses to $B$ tones were set to 217247, 257-287 and 329-359 ms from the $A 1$ onset (67-97, 107-137 and 179-209 ms from the onset of $B$ ). Time windows for analyzing the ERP responses elicited by the $A 2$ tones were set at $365-$ $395,405-435$, and 497-527 ms from the onset of $A 1$ (65-95, 105-135, and 197-227 ms with respect to the onset of $A 2$ ). N1 and N2 amplitudes were measured in two ways: 1) relative to the pre-pattern (i.e., pre-A1) baseline and 2) relative to the mean amplitude of the preceding P1 component. The latter was done in order to test whether these components were separately modulated or together by a slow shift covering the latency range of all three ERP components. For this measurement, the P1 mean amplitude (as defined above) was subtracted from the N1 and N2 amplitudes (again, as defined above). Amplitude measurements were analyzed separately for each tone $(A 1, B$, and $A 2)$, component $(\mathrm{P} 1, \mathrm{~N} 1$, and $\mathrm{N} 2)$, and measurement (relative to the pre-pattern baseline and to P1) by repeated-measures analyses of variance (ANOVAs) with the following factors: Percept (integrated, segregated) $\times$ Laterality (left, middle, right $) \times$ Anteriorposterior (frontal, central, parietal).

\section{Responses to the deviant tones}

For the deviant tones, epochs of $575 \mathrm{~ms}$ duration, commencing $75 \mathrm{~ms}$ before the onset of the $A 2$ tone, were collected. The baseline was set to the 75-ms interval before the $A 2$ onset. Local maxima were identified in the grand average ERP waveforms at the $\mathrm{Cz}$ electrode: Deviants also elicited a positive and two successive negative waveforms, peaking at about 75, 110 (segregated 


\section{Results}

\section{Behavioral measures}

On average the integrated percept was experienced in $48.15 \%$ of the stimulation time $($ S.D. $=10.7 \%)$ in the experimental and in $52.84 \%($ S.D. $=14.6 \%)$ in the control stimulus blocks. The average proportion of the segregated percept was $44.99 \%($ S.D. $=12.2 \%$ ) and $42.76 \%$ $($ S.D. $=14.9 \%)$ in the experimental and control stimulus blocks, respectively. The deviants did not cause significant changes in the proportions of the two percepts (integrated percept: $t(18)=1.31 ; p=.80$, segregated percept $t(18)=-0.67 ; p=.51)$. 


\section{ERP measures}

\section{Responses to the standard tones}

Table 1. summarizes the significant amplitude effects found for the standard tones. Because our study was aimed at finding ERP correlates of perceptual organization, only main effects and interactions involving the Percept factor are referred in the text. Significant main effects of Percept were found for the P1 and N1 components elicited by the Al tones with the segregated responses being positively displaced compared to the integrated ones during the latency range of both components. For the N1 component, also significant interactions were found between Anterior-posterior and Percept and between Laterality and Percept. The scalp distribution of the N1 component was more parietally distributed for the integrated than for the segregated percept (less positive; Figure 2, right panel). This was verified by post-hoc tests showing larger amplitude differences between the integrated and segregated N1 components over parietal than central or frontal electrode sites (Tukey HSD with $d f=36$ : all $p$ values <.05), and on the left side and the midline than over the right electrode sites (Tukey HSD with $d f=36$ : all $p$ values <.05). Note that a modulation of the amplitude of the typically frontocentrally maximal N1 wave should not result in a parietally higher change. No significant Percept effect was obtained for the N2 component.

ANOVAs of the P1 and N1 amplitudes elicited by the $B$ tones yielded significant main effects of Percept, again, reflecting a positive displacement of the segregated compared to the integrated ERP responses. No significant effects including the Percept factor were found for the N2 elicited by the $B$ tones or any of the components elicited by the standard $A 2$ tones.

The ANOVAs of the N1 and N2 amplitudes measured with respect to the preceding P1 peak revealed no significant effect of Percept for any of the tones $(A 1, B$ and $A 2)$, suggesting that the effects of perceptual organization found for the measurements taken with respect to the prepattern baseline for these three components are not independent of each other. 
Figure 2. Left panel: ERP responses elicited by the standard tones at $\mathrm{Cz}$ (red continuous line: integrated, green dotted line: segregated, black continuous line: integrated-minus-segregated difference waveform). Tone onsets are marked by vertical lines and the tones themselves by horizontally oriented rectangles, separately for the $A 1, B$ and $A 2$ tones. ERP measurement windows for the standard-pattern responses are marked by gray vertical bars with the name of the corresponding component on top. Right panel: Scalp topographies for the integrated (top), integratedminus-segregated (middle), and segregated (bottom) P1 and N1 amplitudes (measured in the same windows as for the statistical analyses) elicited by the standard $A l$ (left) and $B$ tones (right). Maps were spline interpolated with a smoothing factor of $10^{-7}$. Common calibration for the color maps is shown on the right side.

Table 1. Significant results of the ANOVAs for the standard $A 1, A 2$, and $B$ tones, separately. ANOVA factors are listed in Methods. The "Reference" column refers to whether the amplitudes were measured with respect to the baseline or the mean amplitude of the preceding P1 response. Degrees of freedom (df), F values, significance levels (p), Greenhouse-Geisser correction factors (where applicable), and $\eta^{2}$ effect sizes are given for each significant effect.

\begin{tabular}{|c|c|c|c|c|c|c|c|c|}
\hline Tone & Component & Reference & ANOVA factor & df & $\mathbf{F}$ & $\mathbf{p}$ & $\begin{array}{l}\text { G-G } \\
\varepsilon \\
\end{array}$ & $\eta 2$ \\
\hline \multirow[t]{6}{*}{ standard $A 1$} & P1 & Baseline & Anterior-posterior & 2,36 & 68.90 & 0.001 & 0.60 & 0.79 \\
\hline & & Baseline & Laterality & 2,36 & 15.85 & 0.001 & 0.76 & 0.47 \\
\hline & & Baseline & Percept & 1,18 & 6.57 & 0.05 & & 0.27 \\
\hline & & Baseline & $\begin{array}{l}\text { Anterior-posterior } \times \\
\text { Laterality }\end{array}$ & 4,72 & 4.50 & 0.05 & 0.51 & 0.20 \\
\hline & N1 & Baseline & Anterior-posterior & 2,36 & 79.68 & 0.001 & 0.61 & 0.82 \\
\hline & & Baseline & Laterality & 2,36 & 12.62 & 0.001 & 0.70 & 0.41 \\
\hline
\end{tabular}


$\begin{array}{lllllll}\text { Baseline } & \begin{array}{l}\text { Anterior-posterior } x \\ \text { Laterality }\end{array} & 4,72 & 7.15 & 0.001 & 0.65 & 0.28\end{array}$

$\begin{array}{lllllll}\text { Baseline } & \text { Anterior-posterior } \times \text { Percept } & 2,36 & 4.60 & 0.05 & 0.56 & 0.20\end{array}$

$\begin{array}{lllllll}\text { Baseline } & \text { Laterality } \times \text { Percept } & 2,36 & 3.91 & 0.05 & 0.87 & 0.18\end{array}$

$\begin{array}{lllllll}\text { P1 Anterior-posterior } & 2,36 & 20.56 & 0.001 & 0.56 & 0.53\end{array}$

$\begin{array}{lllllll}\text { Baseline } & \text { Anterior-posterior } & 2,36 & 38.75 & 0.001 & 0.59 & 0.68\end{array}$

$\begin{array}{lllllll}\text { Baseline } & \text { Laterality } & 2,36 & 6.45 & 0.01 & 0.73 & 0.26\end{array}$

$\begin{array}{lllllll}\text { Baseline } & \begin{array}{l}\text { Anterior-posterior } \times \\ \text { Laterality }\end{array} & 4,72 & 2.79 & 0.05 & 0.82 & 0.13\end{array}$

$\begin{array}{lllllll}\text { P1 Anterior-posterior } \times & 4,72 & 3.07 & 0.05 & 0.68 & 0.15\end{array}$

$\begin{array}{lllllll}\text { Baseline } & \text { Anterior-posterior } & 2,36 & 57.57 & 0.001 & 0.58 & 0.76\end{array}$

$\begin{array}{llllll}\text { Baseline } \quad \text { Laterality } & 2,36 & 7.337 & 0.01 & 0.698 & 0.29\end{array}$

$\begin{array}{llllll}\text { Baseline } & \text { Percept } & 1,18 & 8.336 & 0.01 & 0.317\end{array}$

\begin{tabular}{|c|c|}
\hline Baseline & Anterior-posterior \\
\hline
\end{tabular}

$\begin{array}{llllll}\text { Baseline } \quad \text { Laterality } & 2,36 & 9.00 & 0.01 & 0.91 & 0.33\end{array}$

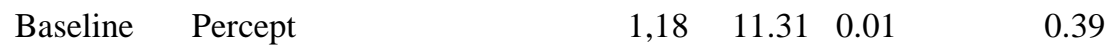

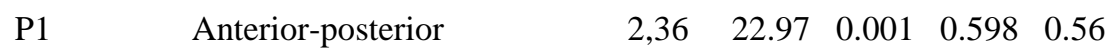

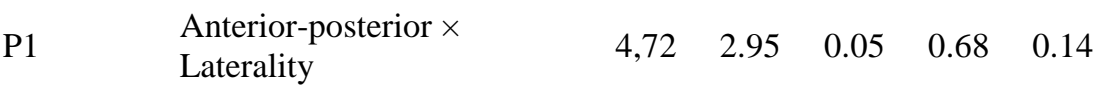

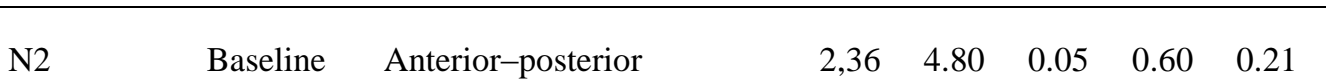

$\begin{array}{llllll}\text { Baseline } \quad \text { Laterality } & 2,36 & 4.97 & 0.05 & 0.94 & 0.22\end{array}$

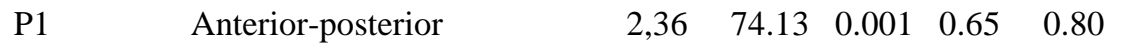

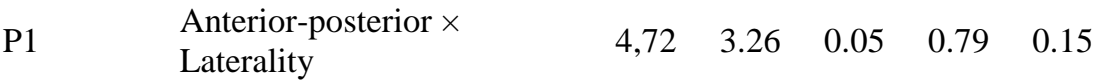

Baseline Anterior-posterior

$\begin{array}{lllll}2,36 & 22.92 & 0.001 & 0.59 & 0.56\end{array}$ 


\section{Responses to the deviant tones}

A significant interaction was found between Percept, Anterior-posterior, and Laterality for the amplitude of the P1 elicited by the deviant tones. The scalp distributions of the integrated-minussegregated differences (Figure 3, bottom panels) mirror the results of the post-hoc tests showing that the difference was smallest over right anterior electrodes (Tukey HSD with $d f=72$ : all $p$ values <.001).

No significant effects were obtained for the N1 amplitude that included the Percept factor. For N2, significant main effects of Percept and Deviant-type were found and both of these factors showed significant interaction with the Anterior-posterior factor. The N2 component elicited by deviants during integrated percept was more negative than that for deviants during segregated percept, and moderate deviants elicited more negative responses than small deviants. The interaction between Percept and Anterior-posterior (Figure 3, bottom panels) was due to larger central and parietal than frontal N2 amplitude differences between the integrated and segregated responses (Tukey HSD with $d f=36$ : all $p$ values $<.001$ ). Deviant-type had a larger effect frontally than over central and parietal regions, causing the interaction with the Anteriorposterior factor (Tukey HSD with $d f=36$ : all $p$ values <.001).

The ANOVA for the P3a elicited by the moderate deviants yielded a significant main effect of Percept (higher P3a amplitudes for segregated than integrated deviants) and an interaction between Percept and Anterior-posterior as well as between Percept and Laterality. These interactions (Figure 3, bottom right panel) were caused by the P3a amplitude difference being larger centrally and parietally than frontally (Tukey HSD with $d f=36$ : all $p$ values $<.001$ ) as 


\section{Deviant Responses}

\section{.......... Segregated \\ Difference}

Small deviant

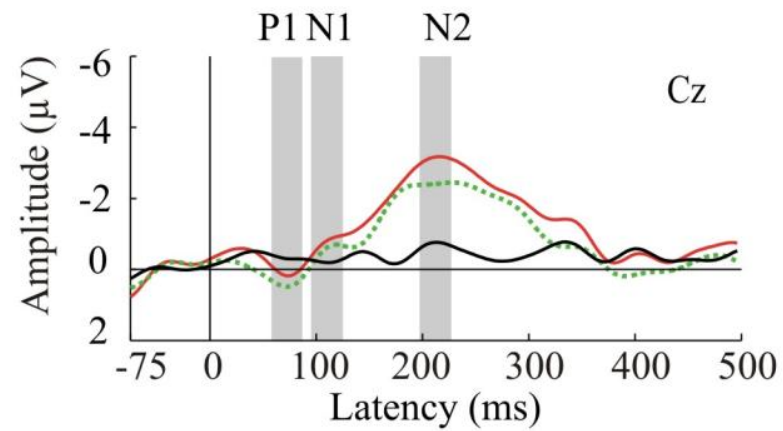

Small deviant
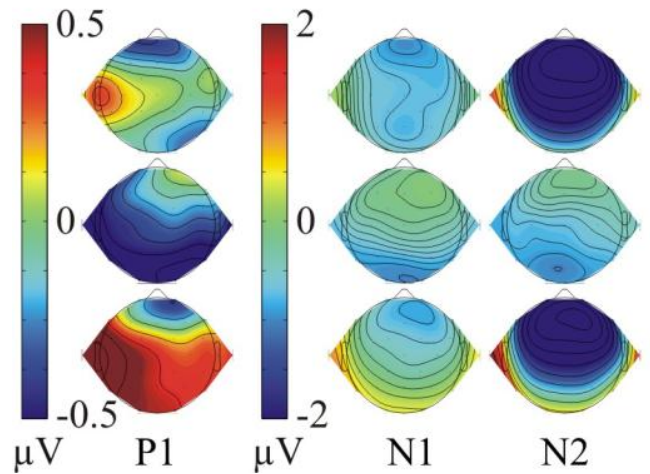

Integrated

Integratedminussegregated Segregated

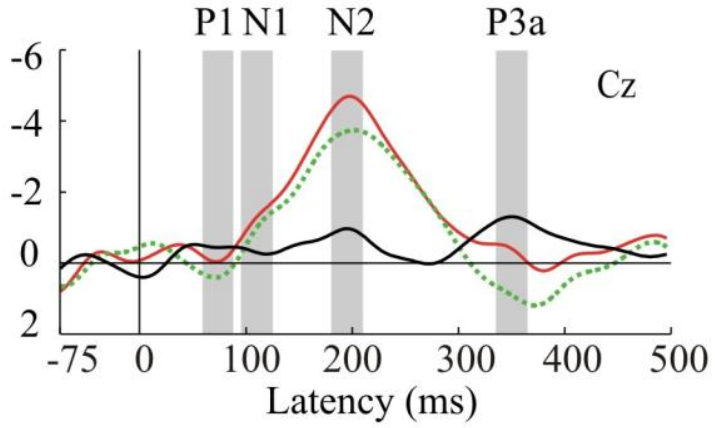

Moderate deviant

Moderate deviant

Figure 3. Top panels: Central $(\mathrm{Cz})$ ERP responses (red continuous line: integrated; green dotted line: segregated; black: integrated-minus-segregated difference waveform) elicited by the small (left panel) and moderate deviants (right panel). ERP measurement windows for the deviant responses are marked by gray vertical bars with the name of the corresponding component on top. Bottom panels (left panel: small deviants, right panel: moderate deviants): Scalp distributions for P1 (extreme left), N1 (left), N2 (middle), and P3a (right, only for the moderate deviants), separately for the integrated (top), integrated-minus-segregated (middle), and segregated (bottom) waveforms. Maps were spline interpolated with a smoothing factor of $10^{-7}$. Separate color map calibrations are provided for P1 (left to the P1 maps) and for the other three components (between the P1 map and the other maps). 
Table 2. Significant results of the ANOVAs for the deviant tones. ANOVA factors are listed in Methods. ANOVA type 'Omnibus' refers to the ANOVA including both small- and the moderate-deviant amplitudes; 'Moderate' refers to the ANOVA for the P3a amplitudes elicited by moderate deviants. (No similar ANOVA was conducted for small deviants, because there were no sign of P3a being elicited by these deviants.) Degrees of freedom (df), F values, significance levels (p), Greenhouse-Geisser correction factors (where applicable), and $\eta^{2}$ effect sizes are given for each significant effect.

\begin{tabular}{|c|c|c|c|c|c|c|c|}
\hline ANOVA type & Component & ANOVA factor & df & $\mathbf{F}$ & $\mathbf{p}$ & $\begin{array}{l}\text { G-G } \\
\varepsilon\end{array}$ & $\eta 2$ \\
\hline \multirow[t]{12}{*}{ Omnibus } & $\mathrm{P} 1$ & Anterior-posterior & 2,36 & 15.88 & 0.001 & 0.71 & 0.47 \\
\hline & & Laterality & 2,36 & 4.574 & 0.05 & 0.89 & 0.20 \\
\hline & & $\begin{array}{l}\text { Anterior-posterior } \times \text { Laterality } \\
\times \text { Percept }\end{array}$ & 4,72 & 2.982 & 0.05 & 0.84 & 0.14 \\
\hline & N1 & Anterior-posterior & 2,36 & 21.95 & 0.001 & 0.57 & 0.55 \\
\hline & & Laterality & 2,36 & 5.13 & 0.05 & 0.88 & 0.22 \\
\hline & $\mathrm{N} 2$ & Anterior-posterior & 2,36 & 46.22 & 0.001 & 0.53 & 0.72 \\
\hline & & Laterality & 2,36 & 21.43 & 0.001 & 0.94 & 0.54 \\
\hline & & Percept & 1,18 & 6.03 & 0.05 & & 0.25 \\
\hline & & Deviant type & 1,18 & 22.07 & 0.001 & & 0.55 \\
\hline & & $\begin{array}{l}\text { Anterior-posterior } \times \text { Deviant } \\
\text { type }\end{array}$ & 2,36 & 15.39 & 0.001 & 0.56 & 0.46 \\
\hline & & Anterior-posterior $\times$ Laterality & 4,72 & 6.52 & 0.01 & 0.7 & 0.27 \\
\hline & & Anterior-posterior $\times$ Percept & 2,36 & 5.93 & 0.05 & 0.6 & 0.25 \\
\hline \multirow[t]{4}{*}{ Moderate } & $\mathrm{P} 3 \mathrm{a}$ & Anterior-posterior & 2,36 & 17.02 & 0.001 & 0.56 & 0.49 \\
\hline & & Percept & 1,18 & 4.63 & 0.05 & & 0.2 \\
\hline & & Anterior-posterior $\times$ Laterality & 4,72 & 3.26 & 0.05 & 0.74 & 0.15 \\
\hline & & Anterior-posterior $\times$ Percept & 2,36 & 7.97 & 0.01 & 0.59 & 0.31 \\
\hline
\end{tabular}




\section{Discussion}

We studied the ERP correlates of processing regular and frequency-deviant sounds in a perceptually bistable stimulus configuration focusing on the stages at which sound processing is modulated by the consciously perceived sound organization. The perceptually bistable stimulation allowed testing the processing of the same acoustic input while perceived sound organization varied.

We found that modulations of both early and late ERP components co-varied with the consciously experienced perceptual organization. Specifically, we found percept-dependent changes in the latency range of the P1, N1, N2, and P3a ERP components. Early (P1 and N1) effects were observed for both regular (both $\mathrm{P} 1$ and N1 elicited by the $A l$ and $B$ tones) and frequency-deviant tones (P1). These results suggest that the currently dominant representation of the auditory environment interacts with perceptual processes already at a very early stage.

For the regular tones, the amplitude of the P1 component elicited by the segregated $A l$ and $B$ tones was more positive than that elicited by the integrated ones. This result is consistent with that of Gutschalk et al. (2005), who found that the P1m component was enhanced when participants reported two streams compared to when they reported one. However, in contrast to Gutschalk et al. (2005) who found that the N1m was higher during the segregated percept, we found that the N1 amplitude was lower for the segregated than for the integrated percept. In fact, our data may be better described as showing a common slow ERP difference waveform overlapping both $\mathrm{P} 1$ and $\mathrm{N} 1$, than as separate modulations of these ERP responses. This is because, except for their amplitude, the scalp distributions obtained in the two latency ranges for the integrated-minus-segregated difference appear to be very similar, while differing between the $A l$ and $B$ tones (see Figure 2, right panel). Further, the integrated-minus-segregated difference for the N1 wave is more pronounced parietally than frontally or centrally, as supported by the significant interaction between the Anterior-posterior and the Percept factors, whereas the N1 scalp distribution has a clear fronto-central maximum. This interpretation is also supported by 
the results of the analysis of the $\mathrm{N} 1$ component measured from the preceding P1 peak, which did not show any percept-dependent effects. Therefore the difference we found between the integrated and segregated N1 components is more likely to have resulted from an early, relatively long-lasting (ca. 60-140 ms) percept-dependent ERP effect, a slow positive displacement of the segregated with respect to the integrated response, rather than from the modulation of the N1 component itself. This slow displacement with a clearly different generator from the well-known obligatory auditory components may reflect the influence of higher levels of the auditory system on the interpretation of the incoming sounds, such as would be model selection assumed by hierarchical predictive coding models (Friston, 2010; Wacongne, Changeux, \& Dehaene, 2012).

A possible source of the contrasting results may stem from Gutschalk et al.'s (2005) instructing their participants to follow either the A tones or the B tones when perceiving two streams, whereas the current instructions did not vary with the experienced percept. Gutschalk et al.'s (2005) instructions may have differentially influenced the N1 amplitude during the perception of the segregated vs. the integrated organization through differences in attention, as the N1 is strongly modulated by attention (Hillyard, Hink, Schwent, \& Picton, 1973). An attention-increased N1 during the segregated percept in Gutschalk et al.'s (2005) experiment could have obscured the small opposite effect observed in the current study. Another possible explanation of the contrast between the current and Gutschalk et al.'s (2005) results is that the $\mathrm{N} 1 \mathrm{~m}$ mainly reflects the tangentially oriented auditory cortical sources of N1, whereas the N1 as measured with EEG also includes contributions from radially oriented auditory cortical generators as well as from generators located outside the auditory cortex, such as the non-specific N1 (Näätänen \& Picton, 1987).

For the deviant tones, we found a similar percept-dependent modulation of the P1, suggesting that Winkler et al. (2005) likely failed to find this effect because of using omissions as deviants (i.e., the deviant event did not include an external stimulus). Therefore, the difference in results between Gutschalk et al. (2005) and Winkler et al. (2005) was probably not brought about by the investigation of standard vs. deviant sounds, but by the specific type of deviance used by Winkler et al. (2005). In summary, the ERP responses elicited by regular and frequency-deviant sounds showed early modulations by the perceived sound organization. Studies on binocular 
rivalry also showed that the neural correlates of perceptual organization appear as early as the P1 and N1 latency range. For example, Valle-Inclan et al. (1999) found that stimuli presented to the dominant eye elicited higher ERP responses compared to stimuli presented to the suppressed eye under rivalrous conditions. Their percept-dependent ERP effects started at $70 \mathrm{~ms}$ from stimulus onset (see also Roeber et al., 2008; Veser, O'Shea, Schroger, Trujillo-Barreto, \& Roeber, 2008).

Late ERP (N2 and P3a) effects of the perceptual organization were only found for deviant sounds. When experiencing the segregated organization, deviants elicited smaller N2 response than when experiencing integration. The P3a elicited by moderate deviants was larger while participants reported segregation than integration. These results indicate that the percept influenced the evaluation of the deviant sounds. Because both N2 and P3a are regarded as electrophysiological correlates of sound evaluation processes, the $\mathrm{N} 2$ finding might be explained by considering that when integration is perceived, the $A 2$ tone (the position in which the deviants occurred) defines the end of the repeating pattern. In contrast, while perceiving segregation, an isochronous sequence of $A$ tones is heard and the information about the cyclical pattern is lost. This interpretation is supported by Hill and colleagues (Hill, Bishop, \& Miller, 2012), who concluded that the relative position of a tone within a sequence provides more important information for auditory grouping than its spectral information. Deviations at the end of a pattern might be regarded by the brain as more important than that in an arbitrary position of a temporally unstructured sequence. This could have resulted in the more negative N2 response for the integrated than for the segregated deviants. Thus the enhanced N2 response for the integrated compared with the segregated deviants may reflect that the former were more informative for sound grouping. The N2 finding is similar to that observed by Winkler et al. (2005), who found a frontocentrally negative difference peaking at $176 \mathrm{~ms}$ from the expected onset of rare omitted tones, which was larger when listeners experienced the stimulus sequence as integrated than when they perceived the same sounds as segregated.

Our P3a results suggest that during perceiving the segregated organization, moderate deviants may have become more attention-catching compared with those encountered while experiencing the integrated organization. Perceiving streams with uniform frequencies may have made frequency-deviants more salient than finding the same when tones with different frequencies have been grouped together. Winkler et al. (2005) found no significant percept-related effect on 


\section{Conclusions}

In conclusion, our results showed multiple interactions between the processing of incoming sounds and the currently dominant representation of the sound sequence. This conclusion is in line with previous ones suggesting that sounds are immediately evaluated within their context (Kilian-Hütten, Valente, Vroomen, \& Formisano, 2011; Sussman, 2007; Winkler, 2007; 
Winkler, Denham, \& Nelken, 2009). The percept-related differences found for the regular and frequency-deviant tones suggest that the current percept influences both the early processing of sounds (reflected in the P1 and N1 components) and the evaluation of deviance (reflected in the $\mathrm{N} 2$ and P3a components), whereas the sensitivity of the auditory system to the amount of frequency deviation does not necessarily change with the perceptual organization.

\section{Acknowledgements}

This study was funded by the EU FP7-ICT-231168-SCANDLE project (acoustic SCene ANalysis for Detecting Living Entities) and the Lendület project awarded to István Winkler by the Hungarian Academy of Sciences (contract number LP2012-36/2012). The experiment was realized using Cogent 2000 developed by the Cogent 2000 team at the FIL and the ICN. Topographies were plotted with the aid of a plug-in for EEGlab (Delorme \& Makeig, 2004) written by Andreas Widmann, University of Leipzig. 


\section{References}

Anstis, S., \& Saida, S. (1985). Adaptation to Auditory Streaming of Frequency-Modulated Tones. Journal of Experimental Psychology- Human Perception and Performance, 11(3), 257-271. doi: 10.1037/0096-1523.11.3.257

Bar, M. (2007). The proactive brain: using analogies and associations to generate predictions. Trends in Cognitive Sciences, 11(7), 280-289. doi: 10.1016/j.tics.2007.05.005

Bendixen, A., Denham, S. L., Gyimesi, K., \& Winkler, I. (2010). Regular patterns stabilize auditory streams. Journal of the Acoustical Society of America, 128(6), 3658-3666. doi: $10.1121 / 1.3500695$

Blake, R., \& Logothetis, N. K. (2002). Visual competition. Nature Reviews Neuroscience, 3(1), 13-23. doi: 10.1038/nrn701

Brancucci, A., \& Tommasi, L. (2011). "Binaural rivalry": dichotic listening as a tool for the investigation of the neural correlate of consciousness. Brain and Cognition, 76(2), 218224. doi: 10.1016/j.bandc.2011.02.007

Bregman, A. S. (1990). Auditory Scene Analysis: The Perceptual Organization of Sound. Cambridge, MA: MIT Press.

Cusack, R., Deeks, J., Aikman, G., \& Carlyon, R. P. (2004). Effects of location, frequency region, and time course of selective attention on auditory scene analysis. Journal of Experimental Psychology- Human Perception and Performance, 30(4), 643-656. doi: 10.1037/0096-1523.30.4.643

Delorme, A., \& Makeig, S. (2004). EEGLAB: An open source toolbox for analysis of single-trial EEG dynamics including independent component analysis. Journal of Neuroscience Methods, 134(1), 9-21. doi: 10.1016/j.jneumeth.2003.10.009

Denham, S. L., Gyimesi, K., Stefanics, G., \& Winkler, I. (2010). Stability of perceptual organisation in auditory streaming. In E. A. Lopez-Poveda, A. R. Palmer \& R. Meddis (Eds.), The Neurophysiological Bases of Auditory Perception. (pp. 477-487). New York: Springer.

Denham, S. L., Gyimesi, K., Stefanics, G., \& Winkler, I. (in press). Perceptual bi-stability in auditory streaming: How much do stimulus features matter? Learning and Perception. 
Denham, S. L., \& Winkler, I. (2006). The role of predictive models in the formation of auditory streams. Journal of Physiology, Paris, 100(1-3), 154-170. doi: 10.1016/j.jphysparis.2006.09.012

Escera, C., Alho, K., Schröger, E., \& Winkler, I. (2000). Involuntary attention and distractibility as evaluated with event-related brain potentials. Audiology and Neuro-Otology, 5(3-4), 151-166. doi: 10.1159/000013877

Friedman, D., Cycowicz, Y. M., \& Gaeta, H. (2001). The novelty P3: an event-related brain potential (ERP) sign of the brain's evaluation of novelty. Neuroscience and Biobehavioral Reviews, 25(4), 355-373. doi: 10.1016/S0149-7634(01)00019-7

Friston, K. (2010). The free-energy principle: a unified brain theory? Nature Reviews Neuroscience, 11(2), 127-138. doi: 10.1038/nrn2787

Gutschalk, A., Micheyl, C., Melcher, J. R., Rupp, A., Scherg, M., \& Oxenham, A. J. (2005). Neuromagnetic correlates of streaming in human auditory cortex. Journal of Neuroscience, 25(22), 5382-5388. doi: 10.1523/JNEUROSCI.0347-05.2005

Helson, H. (1964). Adaptation-level theory: Oxford, England: Harper \& Row.

Hill, K. T., Bishop, C. W., \& Miller, L. M. (2012). Auditory grouping mechanisms reflect a sound's relative position in a sequence. Frontiers in Human Neuroscience, 6, 158. doi: 10.3389/fnhum.2012.00158

Hill, K. T., Bishop, C. W., Yadav, D., \& Miller, L. M. (2011). Pattern of BOLD signal in auditory cortex relates acoustic response to perceptual streaming. BMC Neuroscience, 12, 85. doi: 10.1186/1471-2202-12-85

Hillyard, S. A., Hink, R. F., Schwent, V. L., \& Picton, T. W. (1973). Electrical signs of selective attention in the human brain. Science, 182(108), 177-180. doi: 10.1126/science.182.4108.177

Horváth, J., Winkler, I., \& Bendixen, A. (2008). Do N1/MMN, P3a, and RON form a strongly coupled chain reflecting the three stages of auditory distraction? Biological Psychology, 79(2), 139-147. doi: DOI 10.1016/j.biopsycho.2008.04.001

Kilian-Hütten, N., Valente, G., Vroomen, J., \& Formisano, E. (2011). Auditory cortex encodes the perceptual interpretation of ambiguous sound. The Journal of Neuroscience, 31(5), 1715-1720. doi: 10.1523/JNEUROSCI.4572-10.2011 
Leopold, D. A., \& Logothetis, N. K. (1999). Multistable phenomena: Changing views in perception. Trends in Cognitive Sciences, 3(7), 254-264. doi: 10.1016/S13646613(99)01332-7

Leppert, D., Goodin, D. S., \& Aminoff, M. J. (2003). Stimulus recognition and its relationship to the cerebral event-related potential. Neurology, 61(11), 1533-1537.

Moreno-Bote, R., Shpiro, A., Rinzel, J., \& Rubin, N. (2010). Alternation rate in perceptual bistability is maximal at and symmetric around equi-dominance. Journal of Vision, 10(11), 1-18. doi: 10.1167/10.11.1

Müller, D., Widmann, A., \& Schröger, E. (2005). Auditory streaming affects the processing of successive deviant and standard sounds. Psychophysiology, 42(6), 668-676. doi: 10.1111/j.1469-8986.2005.00355.x

Näätänen, R., \& Picton, T. (1987). The N1 Wave of the Human Electric and Magnetic Response to Sound - a Review and an Analysis of the Component Structure. Psychophysiology, 24(4), 375-425. doi: 10.1111/j.1469-8986.1987.tb00311.x

Picton, T. W. (2010). Human auditory evoked potentials. San Diego: Plural Publishing.

Polich, J. (2007). Updating p300: An integrative theory of P3a and P3b. Clinical Neurophysiology, 118(10), 2128-2148. doi: 10.1016/j.clinph.2007.04.019

Pressnitzer, D., \& Hupé, J. M. (2006). Temporal dynamics of auditory and visual bistability reveal common principles of perceptual organization. Current Biology, 16(13), 13511357. doi: 10.1016/j.cub.2006.05.054

Purves, D., \& Andrews, T. J. (1997). The perception of transparent three-dimensional objects. Proceedings of the National Academy of Sciences of the United States of America, 94(12), 6517-6522. doi: 10.1073/pnas.94.12.6517

Railo, H., Koivisto, M., \& Revonsuo, A. (2011). Tracking the processes behind conscious perception: A review of event-related potential correlates of visual consciousness. Consciousness and Cognition, 20(3), 972-983. doi: 10.1016/j.concog.2011.03.019

Ritter, W., \& Ruchkin, D. S. (1992). A review of event-related potential components discovered in the context of studying P3. Annals of the New York Academy of Sciences, 658, 1-32. doi: 10.1111/j.1749-6632.1992.tb22837.x 
Ritter, W., Simson, R., Vaughan, H. G., \& Friedman, D. (1979). A Brain Event Related to the Making of a Sensory Discrimination. Science, 203(4387), 1358-1361. doi: $10.1126 /$ science. 424760

Roberts, B., Glasberg, B. R., \& Moore, B. C. J. (2002). Primitive stream segregation of tone sequences without differences in fundamental frequency or passband. Journal of the Acoustical Society of America, 112(5), 2074-2085. doi: 10.1121/1.1508784

Roeber, U., Widmann, A., Trujillo-Barreto, N. J., Herrmann, C. S., O'Shea, R. P., \& Schröger, E. (2008). Early correlates of visual awareness in the human brain: Time and place from event-related brain potentials. Journal of Vision, 8(3), 21 21-12. doi: 10.1167/8.3.21

Schadwinkel, S., \& Gutschalk, A. (2011). Transient bold activity locked to perceptual reversals of auditory streaming in human auditory cortex and inferior colliculus. Journal of Neurophysiology, 105(5), 1977-1983. doi: 10.1152/jn.00461.2010

Schröger, E. (1996). A neural mechanism for involuntary attention shifts to changes in auditory stimulation. Journal of Cognitive Neuroscience, 8(6), 527-539. doi: 10.1162/jocn.1996.8.6.527

Snyder, J. S., Alain, C., \& Picton, T. W. (2006). Effects of attention on neuroelectric correlates of auditory stream segregation. Journal of Cognitive Neuroscience, 18(1), 1-13. doi: $10.1162 / 089892906775250021$

Sussman, E., Ritter, W., \& Vaughan, H. G. (1999). An investigation of the auditory streaming effect using event-related brain potentials. Psychophysiology, 36(1), 22-34. doi: $10.1017 /$ S0048577299971056

Sussman, E. S. (2007). A new view on the MMN and attention debate - The role of context in processing auditory events. Journal of Psychophysiology, 21(3-4), 164-175. doi: 10.1027/0269-8803.21.34.164

Valle-Inclan, F., Hackley, S. A., de Labra, C., \& Alvarez, A. (1999). Early visual processing during binocular rivalry studied with visual evoked potentials. Neuroreport, 10(1), 21-25.

van Noorden, L. P. A. S. (1975). Temporal coherence in the perception of tone sequences. Doctoral dissertation, Technical University Eindhoven.

Veser, S., O'Shea, R. P., Schroger, E., Trujillo-Barreto, N. J., \& Roeber, U. (2008). Early correlates of visual awareness following orientation and colour rivalry. Vision Research, 48(22), 2359-2369. doi: 10.1016/j.visres.2008.07.024 
Wacongne, C., Changeux, J. P., \& Dehaene, S. (2012). A neuronal model of predictive coding accounting for the mismatch negativity. The Journal of Neuroscience, 32(11), 3665-3678. doi: 10.1523/JNEUROSCI.5003-11.2012

Winkler, I. (2007). Interpreting the mismatch negativity. Journal of Psychophysiology, 21(3-4), 147-163. doi: 10.1027/0269-8803.21.34.147

Winkler, I., Denham, S. L., \& Nelken, I. (2009). Modeling the auditory scene: predictive regularity representations and perceptual objects. Trends in Cognitive Sciences, 13(12), 532-540. doi: 10.1016/j.tics.2009.09.003

Winkler, I., Takegata, R., \& Sussman, E. (2005). Event-related brain potentials reveal multiple stages in the perceptual organization of sound. Cognitive Brain Research, 25(1), 291-299. doi: 10.1016/j.cogbrainres.2005.06.005 
Table 1. Significant results of the ANOVAs for the standard $A 1, A 2$, and $B$ tones, separately. ANOVA factors are listed in Methods. The "Reference" column refers to whether the amplitudes were measured with respect to the baseline or the mean amplitude of the preceding P1 response. Degrees of freedom (df), F values, significance levels (p), Greenhouse-Geisser correction factors (where applicable), and $\eta^{2}$ effect sizes are given for each significant effect.

\begin{tabular}{|c|c|c|c|c|c|c|c|c|}
\hline Tone & Component & Reference & ANOVA factor & df & $\mathbf{F}$ & $\mathbf{p}$ & $\begin{array}{l}\mathbf{G}-\mathbf{G} \\
\boldsymbol{\varepsilon}\end{array}$ & $\eta 2$ \\
\hline \multirow[t]{14}{*}{ standard $A \boldsymbol{I}$} & $\mathrm{P} 1$ & Baseline & Anterior-posterior & 2,36 & 68.90 & 0.001 & 0.60 & 0.79 \\
\hline & & Baseline & Laterality & 2,36 & 15.85 & 0.001 & 0.76 & 0.47 \\
\hline & & Baseline & Percept & 1,18 & 6.57 & 0.05 & & 0.27 \\
\hline & & Baseline & $\begin{array}{l}\text { Anterior-posterior } \times \\
\text { Laterality }\end{array}$ & 4,72 & 4.50 & 0.05 & 0.51 & 0.20 \\
\hline & N1 & Baseline & Anterior-posterior & 2,36 & 79.68 & 0.001 & 0.61 & 0.82 \\
\hline & & Baseline & Laterality & 2,36 & 12.62 & 0.001 & 0.70 & 0.41 \\
\hline & & Baseline & $\begin{array}{l}\text { Anterior-posterior } \times \\
\text { Laterality }\end{array}$ & 4,72 & 7.15 & 0.001 & 0.65 & 0.28 \\
\hline & & Baseline & Anterior-posterior $\times$ Percept & 2,36 & 4.60 & 0.05 & 0.56 & 0.20 \\
\hline & & Baseline & Laterality $\times$ Percept & 2,36 & 3.91 & 0.05 & 0.87 & 0.18 \\
\hline & & $\mathrm{P} 1$ & Anterior-posterior & 2,36 & 20.56 & 0.001 & 0.56 & 0.53 \\
\hline & $\mathrm{N} 2$ & Baseline & Anterior-posterior & 2,36 & 38.75 & 0.001 & 0.59 & 0.68 \\
\hline & & Baseline & Laterality & 2,36 & 6.45 & 0.01 & 0.73 & 0.26 \\
\hline & & Baseline & $\begin{array}{l}\text { Anterior-posterior } \times \\
\text { Laterality }\end{array}$ & 4,72 & 2.79 & 0.05 & 0.82 & 0.13 \\
\hline & & $\mathrm{P} 1$ & $\begin{array}{l}\text { Anterior-posterior } \times \\
\text { Laterality }\end{array}$ & 4,72 & 3.07 & 0.05 & 0.68 & 0.15 \\
\hline \multirow[t]{3}{*}{ standard $B$} & $\mathrm{P} 1$ & Baseline & Anterior-posterior & 2,36 & 57.57 & 0.001 & 0.58 & 0.76 \\
\hline & & Baseline & Laterality & 2,36 & 7.337 & 0.01 & 0.698 & 0.29 \\
\hline & & Baseline & Percept & 1,18 & 8.336 & 0.01 & & 0.317 \\
\hline
\end{tabular}




\begin{tabular}{|c|c|c|c|c|c|c|c|c|}
\hline & \multirow[t]{5}{*}{ N1 } & Baseline & Anterior-posterior & 2,36 & 29.18 & 0.001 & 0.56 & 0.62 \\
\hline & & Baseline & Laterality & 2,36 & 9.00 & 0.01 & 0.91 & 0.33 \\
\hline & & Baseline & Percept & 1,18 & 11.31 & 0.01 & & 0.39 \\
\hline & & $\mathrm{P} 1$ & Anterior-posterior & 2,36 & 22.97 & 0.001 & 0.598 & 0.56 \\
\hline & & $\mathrm{P} 1$ & $\begin{array}{l}\text { Anterior-posterior } \times \\
\text { Laterality }\end{array}$ & 4,72 & 2.95 & 0.05 & 0.68 & 0.14 \\
\hline & \multirow[t]{4}{*}{$\mathrm{N} 2$} & Baseline & Anterior-posterior & 2,36 & 4.80 & 0.05 & 0.60 & 0.21 \\
\hline & & Baseline & Laterality & 2,36 & 4.97 & 0.05 & 0.94 & 0.22 \\
\hline & & $\mathrm{P} 1$ & Anterior-posterior & 2,36 & 74.13 & 0.001 & 0.65 & 0.80 \\
\hline & & $\mathrm{P} 1$ & $\begin{array}{l}\text { Anterior-posterior } \times \\
\text { Laterality }\end{array}$ & 4,72 & 3.26 & 0.05 & 0.79 & 0.15 \\
\hline \multirow[t]{7}{*}{ standard $A 2$} & \multirow[t]{2}{*}{ P1 } & Baseline & Anterior-posterior & 2,36 & 22.92 & 0.001 & 0.59 & 0.56 \\
\hline & & Baseline & Laterality & 2,36 & 4.65 & 0.05 & 0.90 & 0.21 \\
\hline & \multirow[t]{2}{*}{$\mathrm{N} 1$} & Baseline & Anterior-posterior & 2,36 & 25.11 & 0.001 & 0.58 & 0.58 \\
\hline & & $\mathrm{P} 1$ & Anterior-posterior & 2,36 & 4.59 & 0.05 & 0.558 & 0.20 \\
\hline & \multirow[t]{3}{*}{$\mathrm{N} 2$} & Baseline & none & & & & & \\
\hline & & $\mathrm{P} 1$ & Anterior-posterior & 2,36 & 25.42 & 0.001 & 0.58 & 0.59 \\
\hline & & P1 & Laterality & 2,36 & 18.62 & 0.001 & 0.76 & 0.51 \\
\hline
\end{tabular}


Table 2. Significant results of the ANOVAs for the deviant tones. ANOVA factors are listed in Methods. ANOVA type 'Omnibus' refers to the ANOVA including both small- and the moderate-deviant amplitudes; 'Moderate' refers to the ANOVA for the P3a amplitudes elicited by moderate deviants. (No similar ANOVA was conducted for small deviants, because there were no sign of P3a being elicited by these deviants.) Degrees of freedom (df), F values, significance levels (p), Greenhouse-Geisser correction factors (where applicable), and $\eta^{2}$ effect sizes are given for each significant effect.

\begin{tabular}{|c|c|c|c|c|c|c|c|}
\hline ANOVA type & Component & ANOVA factor & df & $\mathbf{F}$ & $\mathbf{p}$ & $\begin{array}{l}\text { G-G } \\
\varepsilon\end{array}$ & $\eta 2$ \\
\hline \multirow[t]{12}{*}{ Omnibus } & $\mathrm{P} 1$ & Anterior-posterior & 2,36 & 15.88 & 0.001 & 0.71 & 0.47 \\
\hline & & Laterality & 2,36 & 4.574 & 0.05 & 0.89 & 0.20 \\
\hline & & $\begin{array}{l}\text { Anterior-posterior } \times \text { Laterality } \\
\times \text { Percept }\end{array}$ & 4,72 & 2.982 & 0.05 & 0.84 & 0.14 \\
\hline & $\mathrm{N} 1$ & Anterior-posterior & 2,36 & 21.95 & 0.001 & 0.57 & 0.55 \\
\hline & & Laterality & 2,36 & 5.13 & 0.05 & 0.88 & 0.22 \\
\hline & $\mathrm{N} 2$ & Anterior-posterior & 2,36 & 46.22 & 0.001 & 0.53 & 0.72 \\
\hline & & Laterality & 2,36 & 21.43 & 0.001 & 0.94 & 0.54 \\
\hline & & Percept & 1,18 & 6.03 & 0.05 & & 0.25 \\
\hline & & Deviant type & 1,18 & 22.07 & 0.001 & & 0.55 \\
\hline & & $\begin{array}{l}\text { Anterior-posterior } \times \text { Deviant } \\
\text { type }\end{array}$ & 2,36 & 15.39 & 0.001 & 0.56 & 0.46 \\
\hline & & Anterior-posterior $\times$ Laterality & 4,72 & 6.52 & 0.01 & 0.7 & 0.27 \\
\hline & & Anterior-posterior $\times$ Percept & 2,36 & 5.93 & 0.05 & 0.6 & 0.25 \\
\hline \multirow[t]{4}{*}{ Moderate } & P3a & Anterior-posterior & 2,36 & 17.02 & 0.001 & 0.56 & 0.49 \\
\hline & & Percept & 1,18 & 4.63 & 0.05 & & 0.2 \\
\hline & & Anterior-posterior $\times$ Laterality & 4,72 & 3.26 & 0.05 & 0.74 & 0.15 \\
\hline & & Anterior-posterior $\times$ Percept & 2,36 & 7.97 & 0.01 & 0.59 & 0.31 \\
\hline
\end{tabular}




\section{Experimental design}

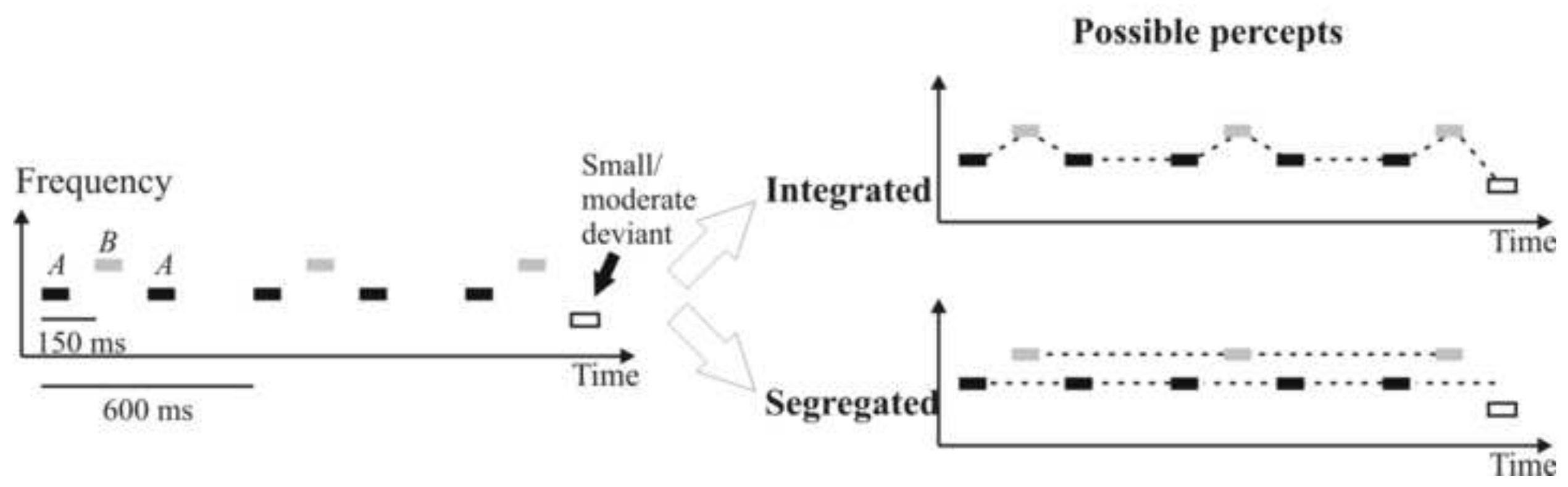




\section{Standard Responses}

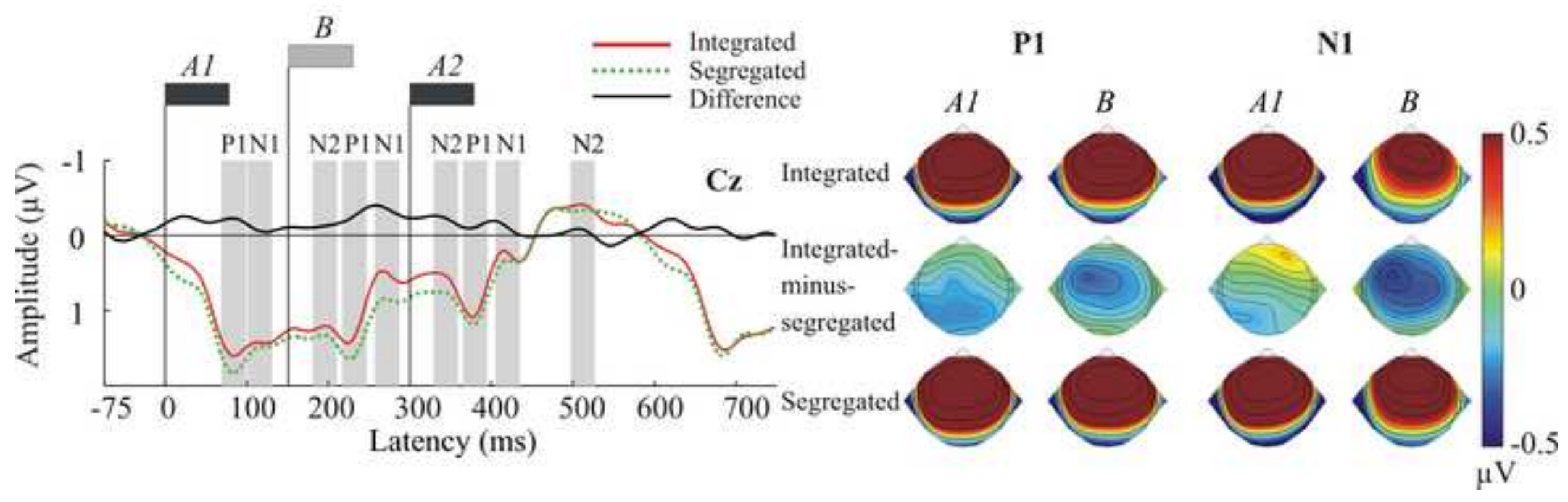




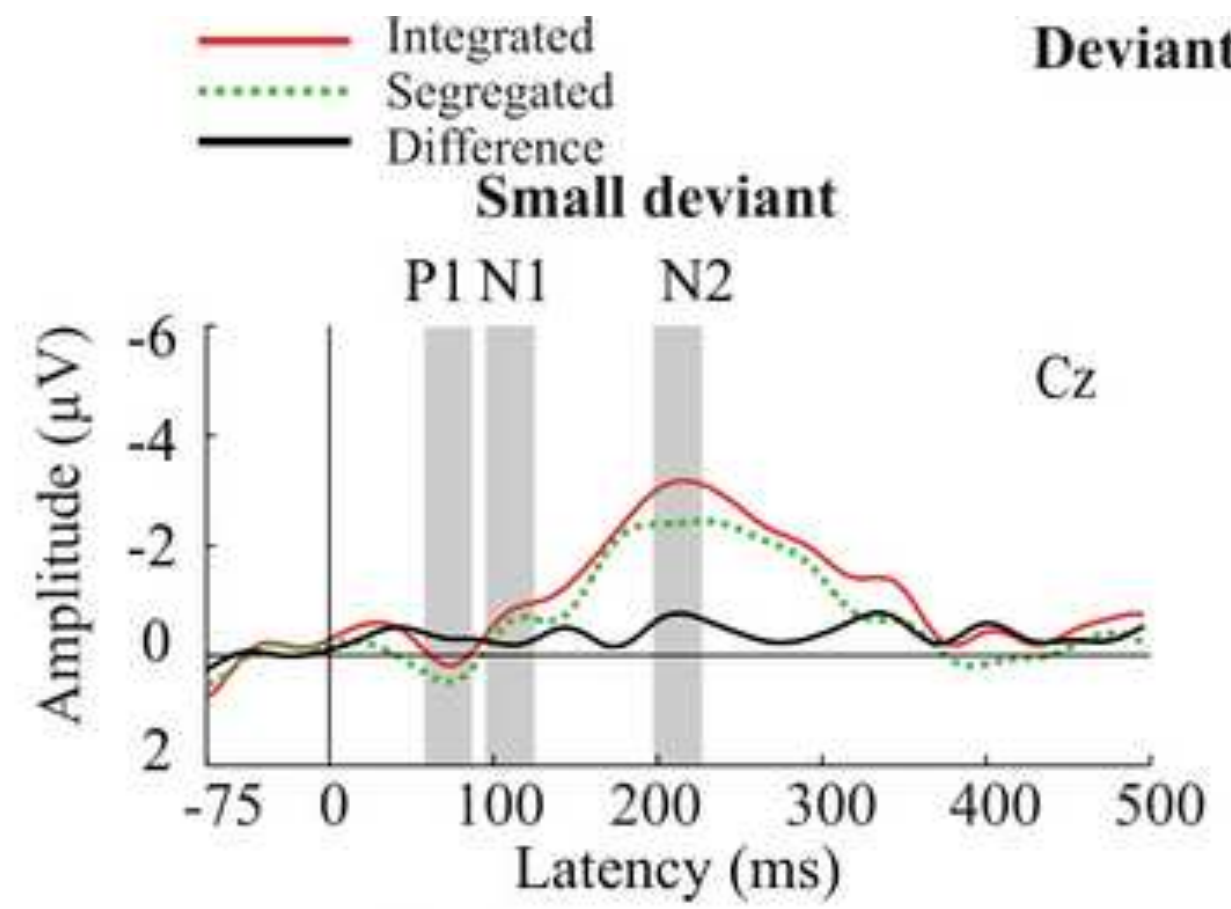

Small deviant

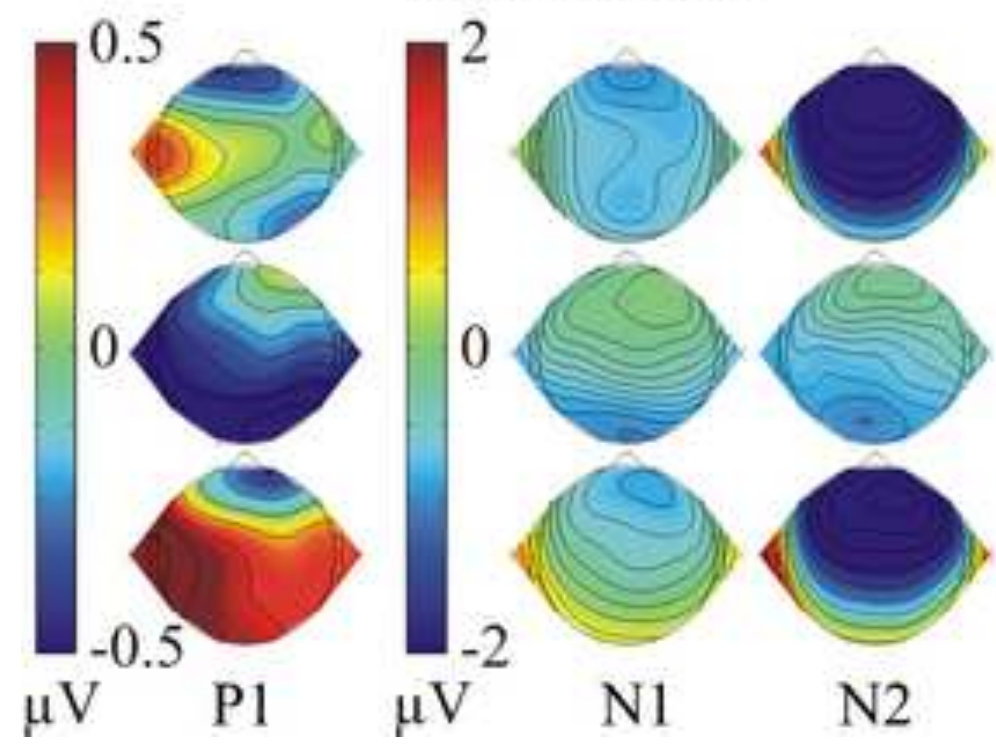

Integrated

Integratedminussegregated Segregated

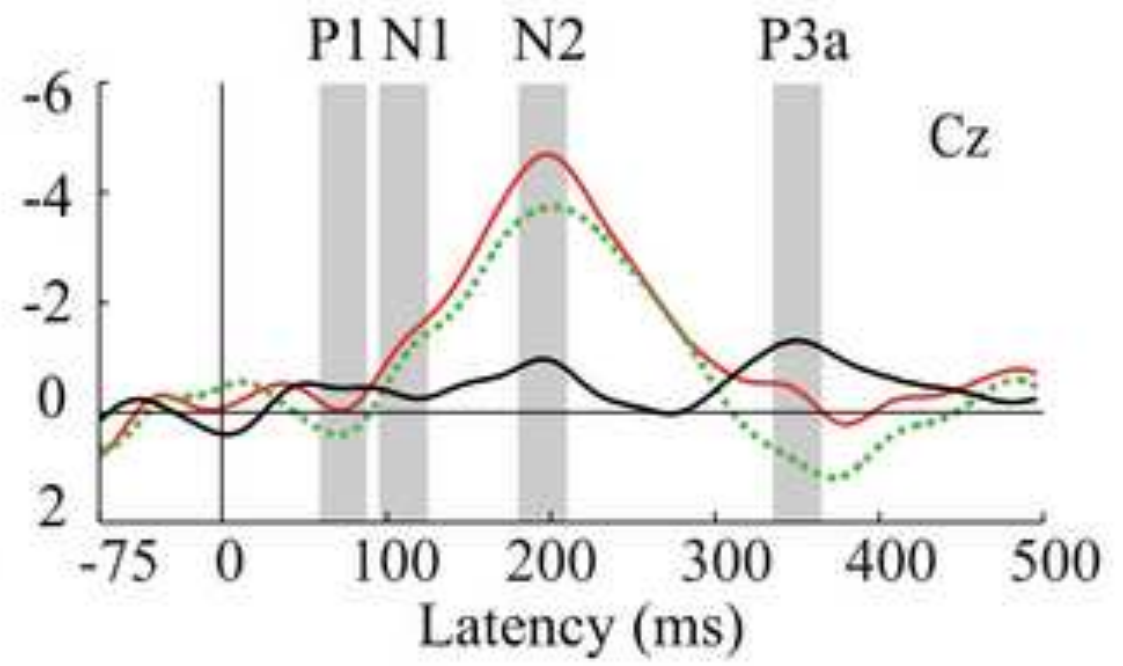

Moderate deviant

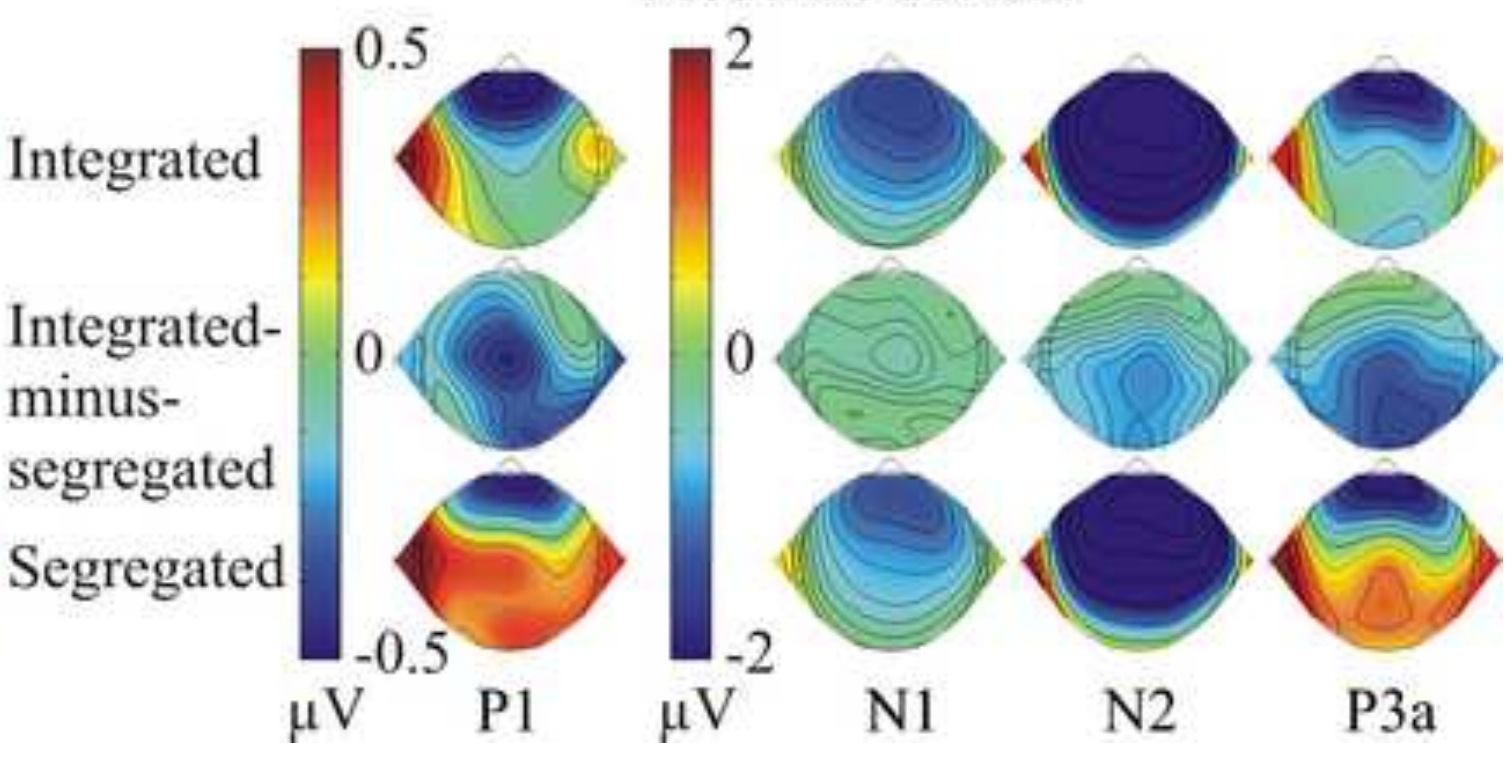

Moderate deviant P1N1 N2 P3a 